\title{
LIFE CYCLE ASSESSMENT OF POLYETHYLENE TEREPTHALATE (PET) BOTTLES
}

\begin{tabular}{|c|c|c|}
\hline $\begin{array}{c}\text { Abhishek Kumar Singh ,Harsh } \\
\text { Agarwal, } \\
\text { Richa Sinha } \\
\text { Department of Production Engineering } \\
\text { Birla Institute of Technology, } \\
\text { Deoghar, India }\end{array}$ & $\begin{array}{c}\text { Sanjay Kumar Jha } \\
\text { Department of Production Engineering } \\
\text { Birla Institute of Technology, Mesra, } \\
\text { Ranchi, India }\end{array}$ & $\begin{array}{c}\text { Anand Prakash } \\
\text { School of General Management } \\
\text { National Institute of Construction } \\
\text { Management and Research, } \\
\text { Pune,India }\end{array}$ \\
\hline
\end{tabular}

\begin{abstract}
This paper deals with the impact of Polyethylene Terepthalate (PET) bottles on earthly ecosystem by performing the Life Cycle Assessment (LCA). This paper discusses a case study on fabrication of PET bottles in the Deoghar region of Jharkhand in India. An attempt has been made in the paper to understand and measure the environmental impacts associated with PET bottles in respect of their processes and activities on wellbeing for environment and human. This research estimates resource requirements and focuses on the journey of PET bottles from cradle to grave by opening perspectives for environmentally sound products and processes.
\end{abstract}

Keywords - Polyethylene Terepthalate (PET); Life Cycle Assessment (LCA); Gabi.

\section{INTRODUCTION}

The consequences of the human impact on the environment have become increasingly apparent in recent years. A number of previously unknown environmental problems have surfaced at local, regional and global levels, in spite of considerable efforts to decrease environmental emissions from identified point sources. As a result of which the focus is now being shifted to the environmental friendly products (Jönsson et.al 1997). From industry there is a demand for methods of improving products from the environmental point of view, both for internal use and for marketing purposes. Life cycle assessment (LCA) is becoming an increasingly important method for making product related environmental assessments. The PET bottles and its other products are widely put to use because of their certain inherent characteristics, such as being lightweight, insulating, durable, elastic, cost efficient, etc. PET bottle works as a perfect packaging material for food products and other useful products. It has become the predominant packaging material for portable drinking water. The recent times have witnessed a surge in the increase about environmental awareness, and business houses are assessing their actions affecting the environment.

LCA is a systematic tool that analyses and evaluates the environmental impacts over the entire lifecycle of a product. It involves tracking down the important stages and components involved over lifecycle of a particular product which includes raw material extraction, manufacturing, product use, recycling and final disposal, identifying and quantifying relevant environmental impacts at each stage. The majority of environmental impacts in the different categories include global warming, acidification, and air pollution come from energy-intensive pre-consumer stages. In our context the prime objectives of carrying out a LCA are:

- To provide a picture as complete as possible of the interactions of an activity with the environment to contribute to the understanding of the overall and interdependent nature of the environmental consequences in production of the PET bottles; and

- To provide decision-makers with the information's identifying the environmental effects of these activities and classifying the opportunities for environmental improvements.

Production of PET Bottles involves the conversion of PET Granules to Pre-forms and later converting to PET Bottles through molding process. The step wise production process is explained in the following process flow diagram (see, Fig 1.0). The Life Cycle Assessment (LCA) in this case has been performed by using the Gabi software. The Gabi follows the method of life cycle assessment (LCA). The International Organization for Standardization published international standards on LCA (International Organization for Standardization (ISO) 2004; International Organization for Standardization (ISO) 2006. Emissions from the past (infrastructure construction), the present (e.g. heating) and the future (e.g. disposal options) have been included in the inventory analysis, virtually without temporal boundaries. Emissions that occur over large time frames of substantially more than 100 years are assigned to specific subcategories (labeled "long-term").These processes release pollutants to "air, low population density", to "water, river" and to "water, ground-“ for a very long time scales. The Gabi database contains corresponding long-term subcategories in order to distinguish these long-term emissions from the ones occurring within the first 100 years. 


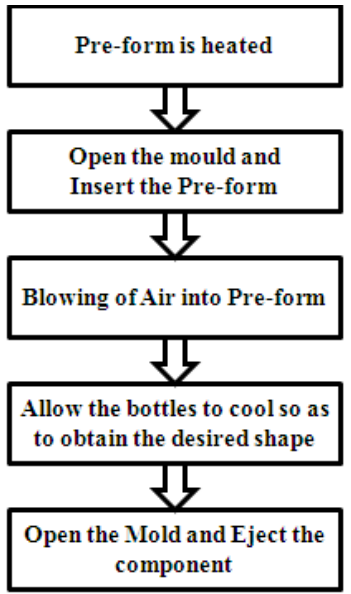

Fig 1.0 Flow Diagram depicting the PET Bottle Manufacturing Process

The analyses of technical processes required to manufacture products and deliver services are based on pure environmental process chain analysis. According to ISO 14040 (International Organization for Standardization (ISO) 2006) several criteria are used to decide which inputs to be studied, including a) mass, b) energy, and c) environmental relevance. The Process diagram has been obtained using the Gabi software which is shown in Fig 2.0.

\section{LITERATURE REVIEW}

The concept of Life Cycle Analysis was in its early stage in the 1960s, as researchers were concerned about the swift exhaustion of fossil fuels so they developed it as an approach to identify with the impact of energy consumption. In 1969, the Midwest Research Institute (and later, Franklin Associates) initiated a study of the Coca-Cola Company to determine which type of beverage container had the lowest releases to the environment and made the fewest demands for raw materials and energy. In the 1970s, the U.S. Environmental Protection Agency (EPA) refined this methodology, creating an approach known as Resource and Environmental Profile Analysis (REPA). Approximately 15 REPAs were performed between 1970 and 1975, driven by the oil crisis of 1973 Bevilacqua et.al. (2012).

In the late 1970s and early 1980s, environmental concern shifted to issues of hazardous waste management. As a result, life cycle logic was incorporated into the emerging method of risk assessment, which was used with increasing frequency in the public policy community to develop environmental protection standards.

When solid waste became a worldwide issue in the late 1980s, the life cycle analysis method developed in the REPA studies again became a tool for analyzing the problem.
LCA OF PET BOTILES

Processes plan Mass $[\mathrm{Kg}]$

The names of the basic processes are shown

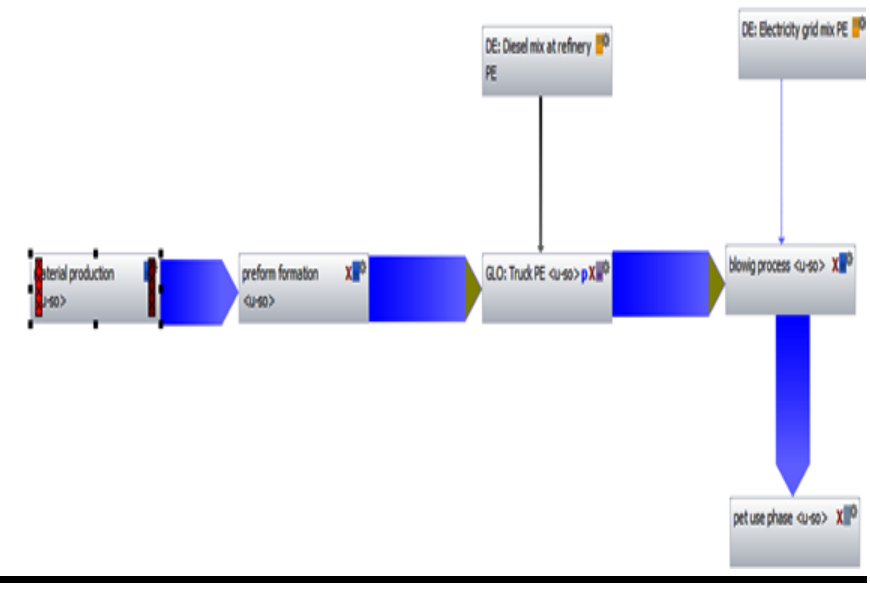

Fig 2.0: Process flow diagram obtained using Gabi

In 1990, for example, a life cycle assessment was completed for the Council for Solid Waste Solutions, which compared the energy and environmental impacts of paper to that of plastic grocery bags. Environmental groups around the world have also adopted life cycle analysis; organizations such as Blue Angel, Green Cross, and Green Seal use and continue to improve LCA for the purpose of product labeling and evaluation. Thus, while initially limited to the public sector, LCA has been adopted by increasing numbers of corporations and nonprofit organizations as an aid to understanding the environmental impacts of their actions.

Over the past 10 years or more, limited numbers of popular academic studies relating to Life Cycle Assessment (LCA) have been published. Many researchers have tried to define the inventory of relevant inputs and outputs of a product or system that constitute a LCA model. Jönsson et.al (1997) recognized the basics of LCA by using the EPS method. He dealt with three type of flooring material - Linoleum, Vinyl Flooring, and Solid Wood Flooring which focused on long term environmental effects of the land filling of building waste. Hochschorner \& Finnveden (2003) chose to perform the comparitive study of two LCA methods, Material Energy Chemicals and Others (MECO) method and Environmentally Responsible Product Assessment (ERPA) matrix method. They further discussed about the relevance to focus on material inflows early in the process, since information on these is easier to access than information on emissions. However there are certain challenges faced during LCA, such as data unavailability and reliability of data. Guinee et al. (2010) have discussed about the evaluation of LCA by using work done for the CALCAS (Co-ordination Action for innovation in Life Cycle Analysis for Sustainability).For performing the LCA of polymer products derived by 


\section{Asia Pacific Journals}

petroleum the Eco invent v1.2 database, the EPA Tool for the Reduction and Assessment of Chemical and other environmental impacts such as eutrophication, acidification can be used (Tabone et. al.2010). McManus \& Taylor (2015) examines LCA's on-going evolution and its use within bioenergy deployment

On closely reviewing these works it has become pertinent to go on with additional research relating to the LCA of PET bottles especially in the context of Jharkhand, India. While the process of a life-cycle assessment might seem simple enough in principle, in practice it is subject to a number of practical limitations. In performing the inventory, system boundaries must be chosen so that completion of the inventory is possible, given the resources that are available. Even if sufficient resources are available, the time required to perform a comprehensive life cycle inventory may be limiting.

This is not to say that life-cycle assessments are without value. Rather, despite the uncertainties involved, these assessments provide invaluable information for decision-making and product stewardship. They allow environmental issues to be evaluated strategically, throughout the entire product life cycle. The challenge is to take advantage of these valuable features of life cycle assessments while bearing in mind the difficulties and uncertainties Dogan (2008).

\section{RESEARCH METHODOLOGY}

The research methodology aids the researcher in allocation of limited resources by posing crucial choices. Our study's scope includes manufacture of PET bottles, distribution to retail, disposal by the consumer into either municipal waste or recycling, material recovery of recycled bottles, and reclamation of recycled polyethylene terephthalate (PET) to form secondary resins. An indigenous model is used by all life cycle stages to provide resource and emissions data for fuel production, electricity, combustion, and transport. The selection of products and services to be analyzed mainly relies on the market (and consumption) situation in Deogarh, Jharkhand. It was also necessary to describe certain production processes which take place outside the Rituraj Packaged Mineral Water plant situated at Deoghar, Jharkhand, India because these products play an important role in the further analyses. The methodology of LCA generally consists of Goal and Scope Definition, Inventory Analysis, Impact Assessment and Interpretation.

\section{A. Goal and Scope Definition}

This component consists of defining the purpose of the study and its scope, establishing the functional unit and establishing a procedure for quality assurance of the study. Our study's scope includes manufacture of PET bottles. The life cycle assessment (LCA) includes the impacts generated by these processes directly, as well as the impacts due to support and infrastructure processes required to perform the transformations. A core model is used by all life cycle stages to provide resource and emissions data for fuel production, electricity, combustion, and transport. The process inventory data in our model come from outside sources, and so our results reflect methodological decisions made by the authors of those sources. Our system boundary is largely defined by these data sources.

\section{B. Inventory Analysis}

In the inventory analysis, the systems studied and their system boundaries are defined and process flow charts are drawn. Once the system has been subdivided into its component subsystems, the data are gathered. The data gathered comprise production, resource use, energy use, emissions to air and water and waste generation (See, Fig 3.0)

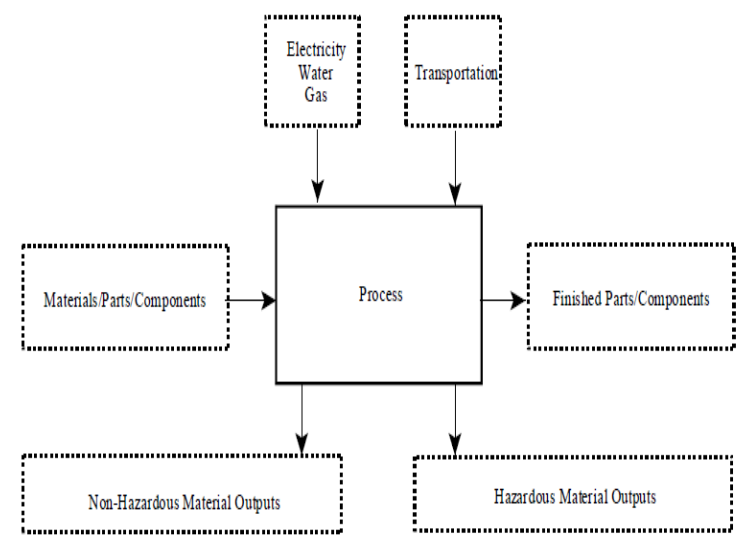

Fig: 3.0 Generic Unit Process (Adopted from Assessment, (2006).

\section{Data Acquisition}

Inputs and outputs required for the means of production and the infrastructure of a production process are recorded separately. As far as possible mass and energy flows of such equipment are shown on a per unit basis (e.g., one refinery of 5 Mio. tons of output, etc.). The Gabi database supports the calculation of results with and without infrastructure. It is recommended to use always inventory data including the infrastructure unless it is intended to make very specific analytical assessments. Life Cycle Inventories (LCI) and Life Cycle Inventory Analysis (LCIA) results of a product system excluding infrastructure may be substantially incomplete and special care must be taken when using these results.

\section{Electricity \& Thermal Energy Consumption}

Electricity is consumed based on the delivered mixes and as far as possible according to the economic situation. In particular situations, individual electricity mixes may be applied. The database distinguishes between production and supply mixes. Processes with region-specific electricity demand use the corresponding supply mix. The production mix is only used within the electricity sector's model.

When a process requires an energy carrier for (process or space) heating, two cases can be distinguished:

- Operational emissions, efficiency etc. of the blow mold machine is known. In this case these particular 


\section{Asia Pacific Journals}

data are used and eventually completed by generic information about infrastructure and / or generic emission factors.

- If only the amount of energy and the kind of energy carrier is known, generic furnace datasets delivering useful heat are used. Boiler datasets such as "light fuel oil, burned in industrial furnace $1 \mathrm{MW}$, nonmodulating" and "heat, light fuel oil, at industrial furnace $1 \mathrm{MW}$ ", respectively, are chosen depending on whether final or useful energy Figs are available.

- In some cases additional air emissions due to the use of different energy carriers have been calculated based on the assumptions for industrial heating.

\section{E. Data Assumption}

Preliminary unit process raw data can be evaluated using current impact assessment methods (and current LCI results). This procedure helps to identify inputs and outputs that contribute substantially to the overall score of the unit process at issue. In a second turn, information about the identified inputs and outputs can be refined if necessary. If no information about the amount of a release or if no specific information about the exact substance emitted is available, an educated guess is made based on plausibility considerations. In cases where such an assumption dominated the LCA result, further and more detailed investigations were carried out and some of the values were reconsidered. If the rough assumption does not influence the result, it does not harm and is kept in the inventory (See Table 1.0).

F. Impact Assessment and Interpretation

The impact assessment is a quantitative and/or qualitative process to characterize and assess the effects of the environmental burdens quantified in the inventory analysis. The process may be divided into three steps: classification, characterization and valuation. The results should be presented in a manner that is consistent with the objective of the study. This step involves presenting the results, writing recommendations and solutions for decision makers. The result is compared with the initial goal and conducted with sensitivity and uncertainty analysis. As per the data collected and analysis done in $\mathrm{GaBi}$ software we came to the following conclusion about environmental that are hazardous and should be considered in the healthy life style of people. The Fig 4.0 represents the acidification caused in the environment by Diesel mix at refinery, electricity grind mixing machine and truck transportation.

\begin{tabular}{|c|c|c|c|}
\hline Product & Raw Material & $\begin{array}{l}\text { Raw Material } \\
\text { Consumption } \\
\text { for } 1 \text { tonne of } \\
\text { product }\end{array}$ & $\begin{array}{l}\text { Electricity } \\
\text { Consumptio } \\
\text { n } \\
\text { (kWh/tonne) }\end{array}$ \\
\hline Ethylene(Teşkilatı,2001) & Light Naptha & $3.2-3.4$ & $44-54$ \\
\hline Ethylene Glycol (Teşkilatı,2001) & Ethylene & 0.6 & 461 \\
\hline P-xylene & Heavy Naptha & 4.3 & 38 \\
\hline \begin{tabular}{|ll} 
Pure $\quad$ Trepthalic & acid \\
(Teşkilatı,2001)
\end{tabular} & P-xylene & 0.665 & 450 \\
\hline \multirow[t]{2}{*}{ PET resins } & Ethylene Glycol & $0.32-0.335$ & \multirow[t]{2}{*}{5138} \\
\hline & $\begin{array}{l}\text { Pure Terepthalic } \\
\text { acid }\end{array}$ & $0.82-0.87$ & \\
\hline $\begin{array}{l}\text { PETchips } \\
\text { (Doğan 2008). }\end{array}$ & PET Resin & - & $251-260$ \\
\hline TOTAL & & & 6328-6395 \\
\hline
\end{tabular}

Table 1.0 Unit Consumptions for 1 tonne Product

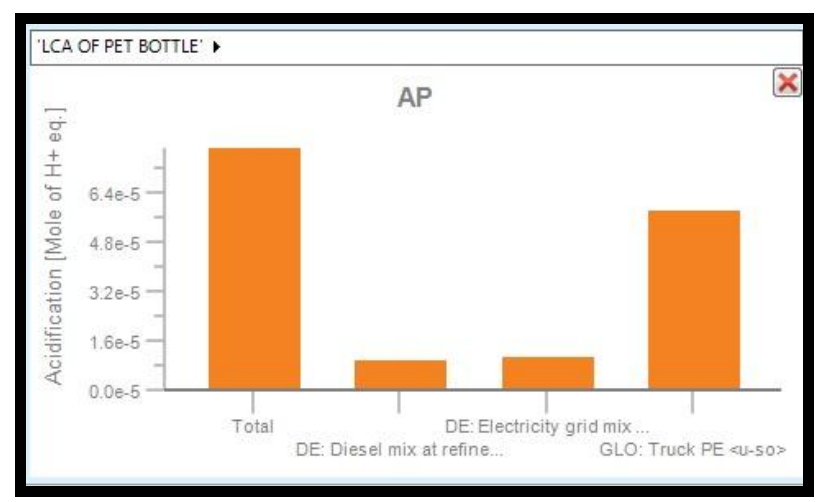

Fig 4.0: Acidification in the Environment

The Fig 5.0 represents the Climate Change caused in the environment by Diesel mix at refinery, electricity grind mixing machine and truck transportation.

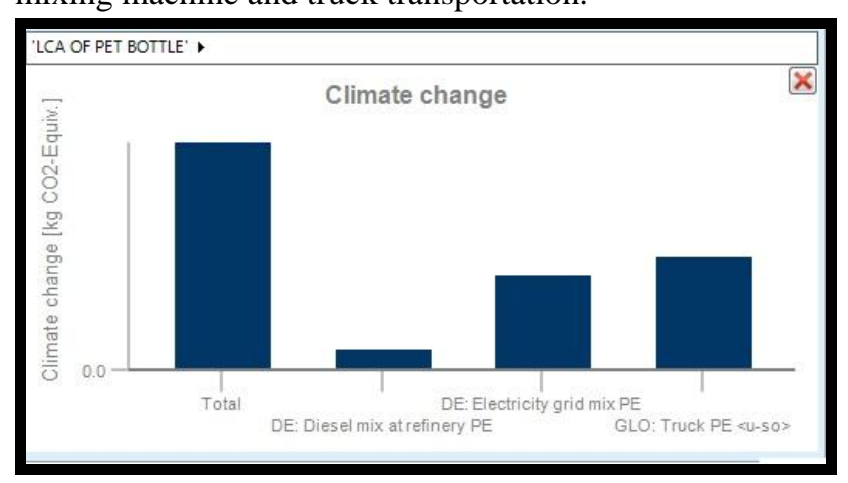

Fig 5.0: Climate Change

The Fig 6.0 represents the Eutrophication caused in the environment by Diesel mix at refinery, electricity grind mixing machine and truck transportation. 


\section{Asia Pacific Journals}

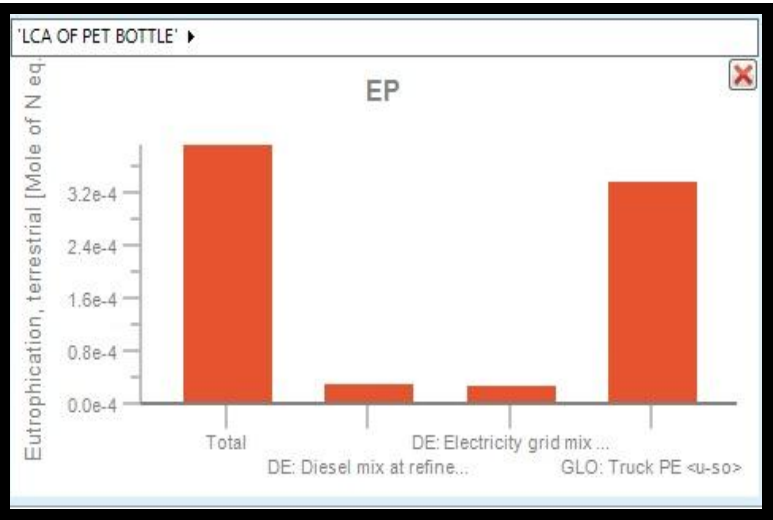

Fig 6.0: Eutrophication

The Fig 7.0 represents the Fossil Depletion caused in the environment by Diesel mix at refinery, electricity grind mixing machine and truck transportation.

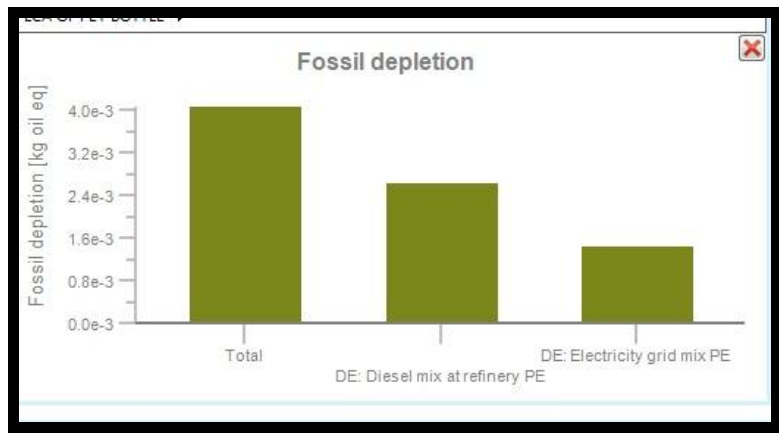

Fig 7.0: Fossil Depletion

The Fig 8.0 represents the Freshwater Eco toxicity caused in the environment by Diesel mix at refinery, electricity grind mixing machine and truck transportation.

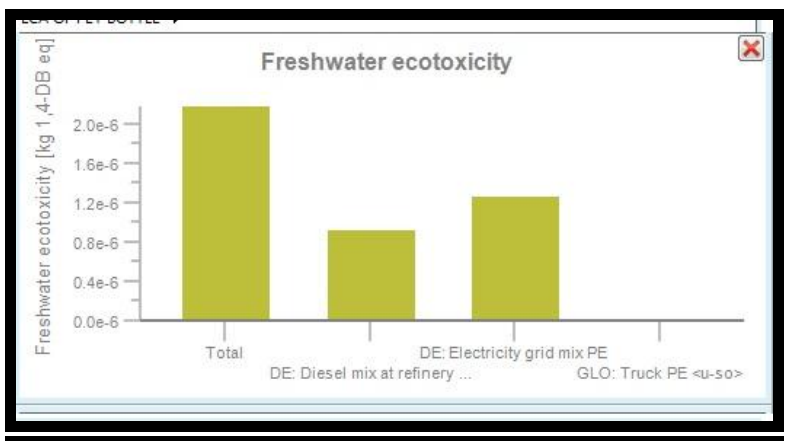

Fig 8.0: Freshwater Eco toxicity

The Fig 9.0 represents the Freshwater Eutrophication caused in the environment by Diesel mix at refinery, electricity grind mixing machine and truck transportation.

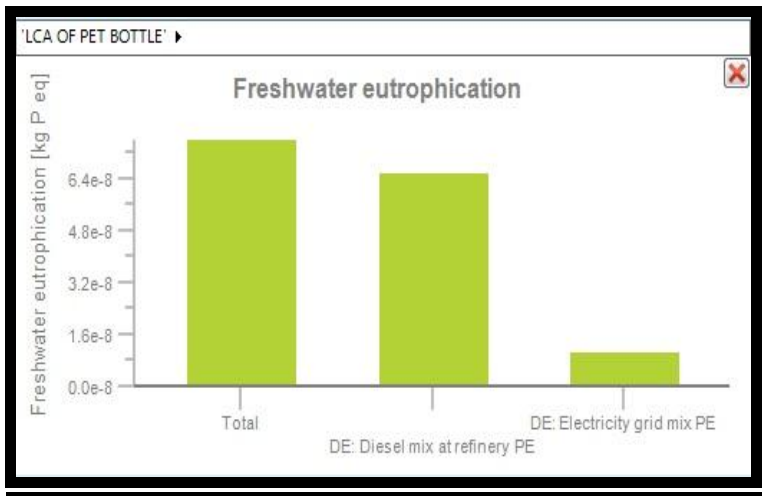

Fig 9.0: Freshwater Eutrophication

The Fig 10.0 represents the Gross water pollution caused in the environment by Diesel mix at refinery, electricity grind mixing machine and truck transportation.

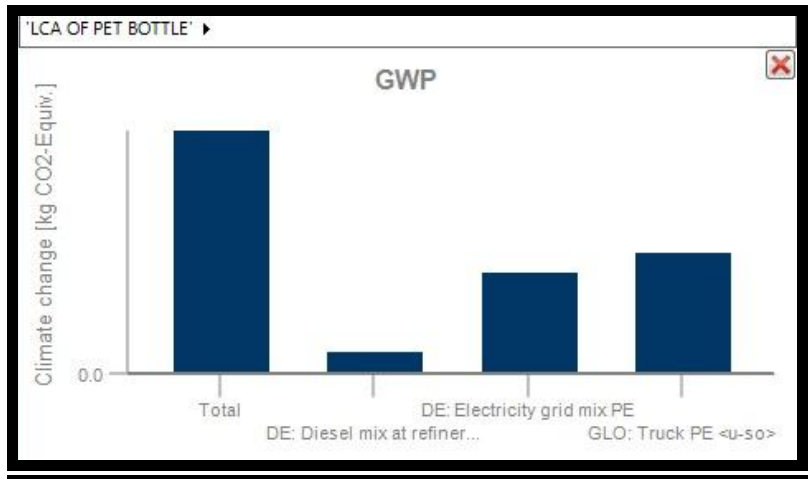

Fig 10.0: Gross Water Pollution

The Fig 11.0 represents the Human Toxicity causing Cancer caused in the environment by Diesel mix at refinery, electricity grind mixing machine and truck transportation.

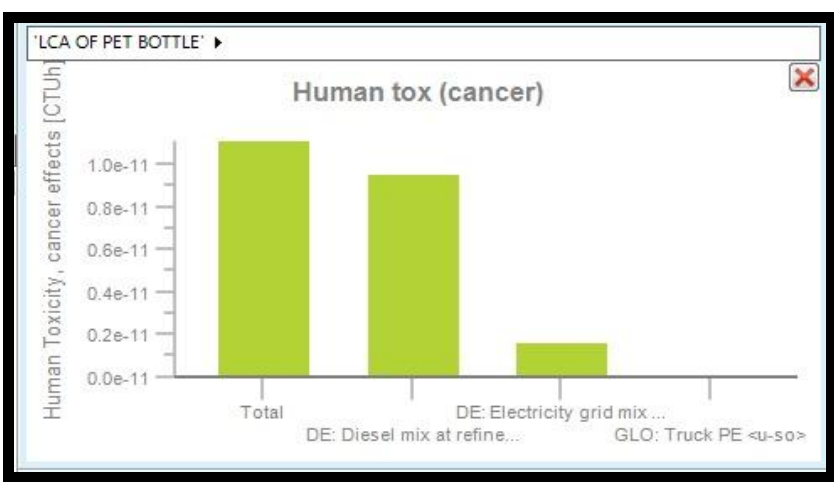

Fig 11.0: Human Toxicity (Cancer)

The Fig 12.0 represents the Human Toxicity (Non Cancer) caused in the environment by Diesel mix at refinery, electricity grind mixing machine and truck transportation. 
ELK

\section{Asia Pacific Journals}

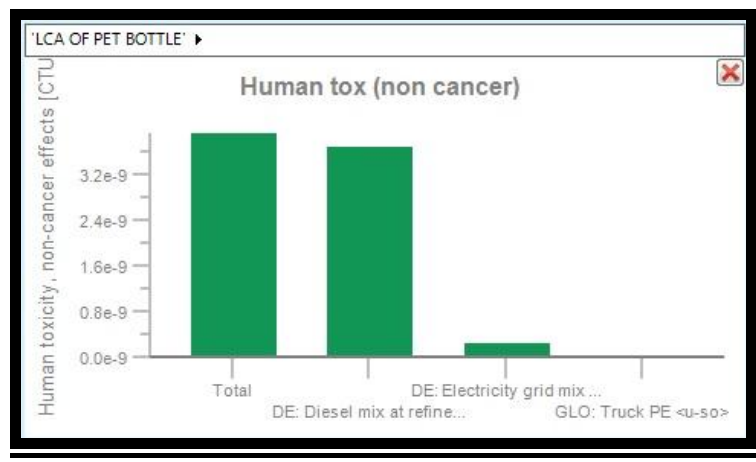

Fig 12.0: Human Toxicity (Non Cancer)

The Fig 13.0 represents the Human Toxicity caused in the environment by Diesel mix at refinery, electricity grind mixing machine and truck transportation.

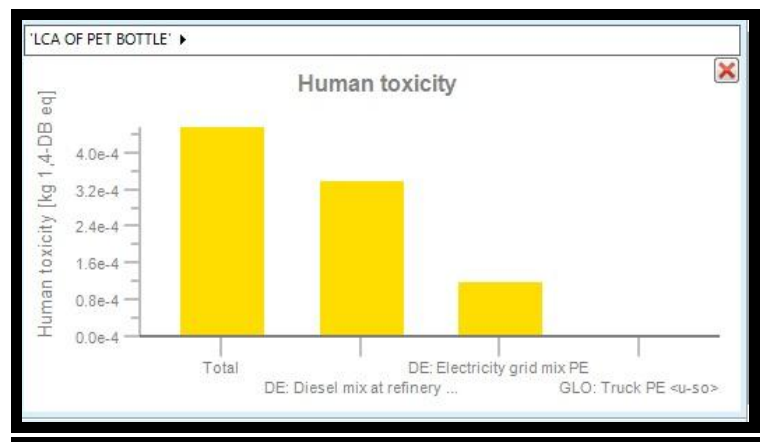

Fig 13.0: Human Toxicity

The Fig 14.0 represents the Ionising Radiation caused in the environment by Diesel mix at refinery, electricity grind mixing machine and truck transportation.

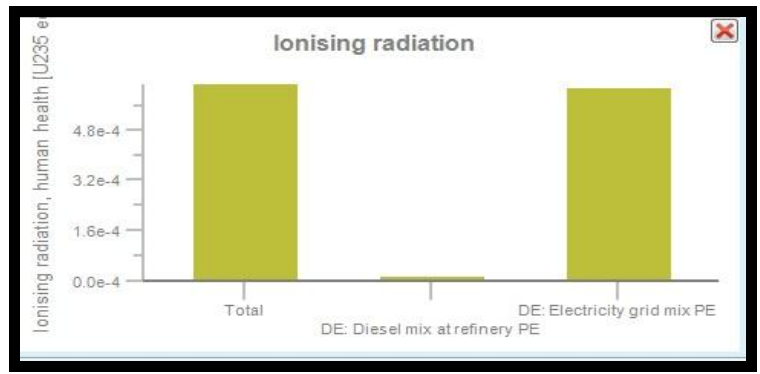

Fig 14: Ionising Radiation

The Fig 15.0 represents the Ozone Depletion caused in the environment by Diesel mix at refinery, electricity grind mixing machine and truck transportation.

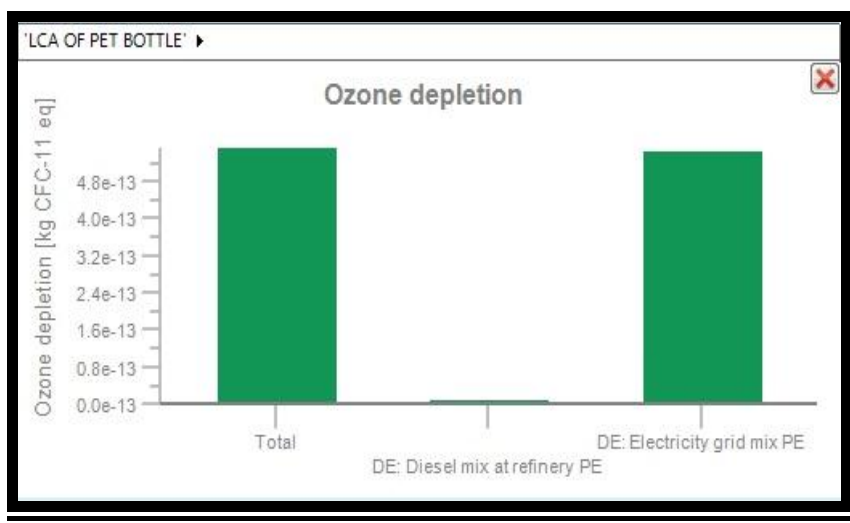

Fig 15.0: Ozone Depletion

The Fig 16.0 represents the Particulate Matter caused in the environment by Diesel mix at refinery, electricity grind mixing machine and truck transportation.

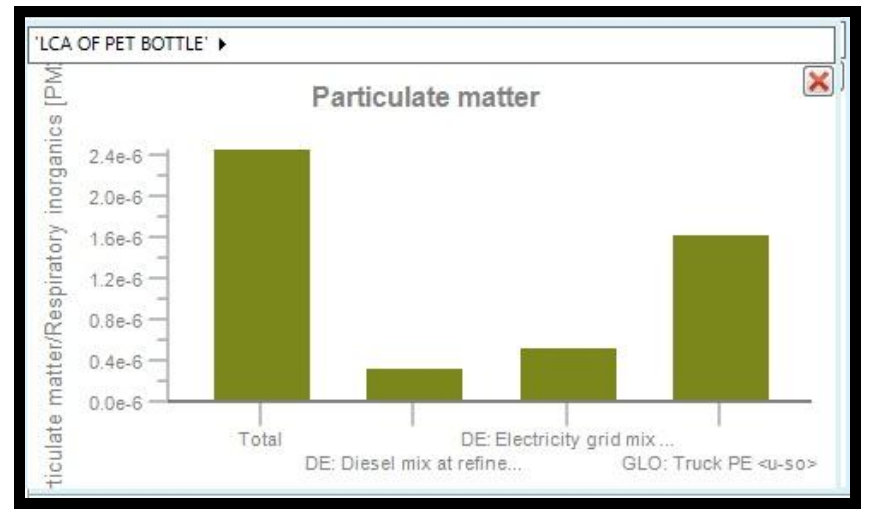

Fig 16.0: Particulate Matter

The Fig 17.0 represents the Photochemical Ozone Formation caused in the environment by Diesel mix at refinery, electricity grind mixing machine and truck transportation.

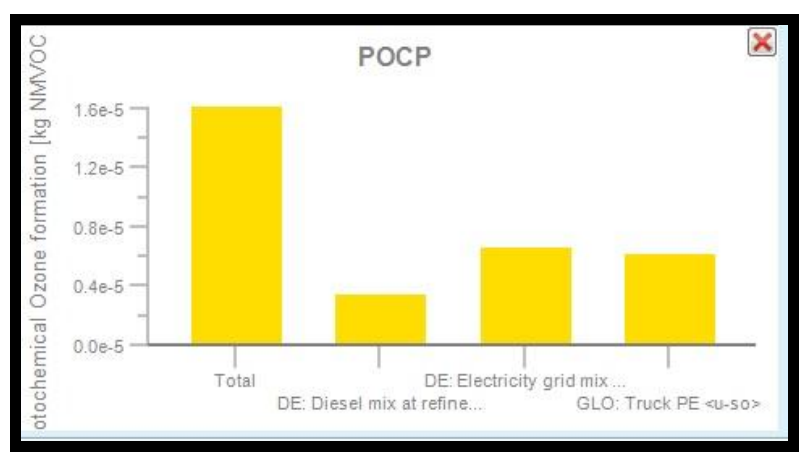

Fig 17.0: Photochemical Ozone Formation 


\section{Asia Pacific Journals}

\section{CONCLUSION}

PET market has gone quite forward in these twenty years. Because of the fact that PET is light and has impermeability to oxygen and carbon dioxide, it is largely used by the soft drink market. PET bottles now have a big share in the water bottle market recently because of the fact that it is durable and unbreakable and does not cause any changes in the transparency and doesn't interfere and contaminate the taste of water also. We have estimated that in Deoghar - the average PET market to be 60 percent bottled water. On average, $1 \mathrm{~kg}$ of polymer contains $961 \mathrm{~g}$ primary resin and $39 \mathrm{~g}$ secondary (recycled) resin. $1 \mathrm{~kg}$ of polymer will package 38.2 liters of bottled water. PET bottles come with caps and labels made of polypropylene (PP). About $5 \mathrm{~g}$ of $\mathrm{PP}$ are used per liter of bottled water. In our model we haven't considered the production of the mineral water, secondary packaging, resin additives, or impacts from retail and marketing.

Plastic has become a fixture in our lives and we have to accept this as a reality. It is next to impossible to completely eliminate the usage of PET. In that case what must be done? According to our discussion, the consumption of natural resource in the production processes must be reduced to the very least, and the emissions and wastes must be prevented by controlling. Wise use after the End of the product life phase is a very vital aspect that has to be kept in mind in order to curb down its detrimental effects on the environment.

\section{Acknowledgment}

We are very thankful to Mr. Anant Singh of "Rituraj packaged Mineral Water Private Ltd." Deoghar, and Mr. Shubhanshu Shekhar Shukla of Byju's Classes, New Delhi for their valuable help and support in completion of this case study.

\section{References}

[1] Assessment, L. C. (2006). Principles and Practice. US Environmental Protection Agency (EPA). EPA/600/R-06/060, May.

[2] Bevilacqua,M., Ciarapica,F.E., \& Giacchetta, G. (2012).Design for Environment as a Tool for the Development of a Sustainable Supply Chain SpringerLink : Bücher.Springer Science \& Business Media, 2012.ISBN:144712460X, 9781447124603

[3]DOĞAN, S. K. (2008). Life Cycle Assessment of Pet Bottle.

[4] Guinee, J. B., Heijungs, R., Huppes, G., Zamagni, A., Masoni, P., Buonamici, R., \& Rydberg, T. (2010). Life cycle assessment: past, present, and future $\uparrow$. Environmental science \& technology, 45(1), 90-96.

[5] Hochschorner, E., \& Finnveden, G. (2003). Evaluation of two simplified life cycle assessment methods. The International Journal of Life Cycle Assessment, 8(3), 119-128.

[6]ISO, I. (2004). 14001: Environmental management systems-Requirements with guidance for use. International Standards Organization. Available at: http://www.iso.org/iso/catalogue_detail?csnumber=31807. Accessed: Accessed: February 19, 2014.
[7] ISO (2006).14040:2006: Environmental management, Life cycle assessment, Principles and framework.

http://www.iso.org/iso/catalogue_detail?csnumber=37456, Accessed: February 24, 2016.

[8] Jönsson, Å., Tillman, A. M., \& Svensson, T. (1997). Life cycle assessment of flooring materials: case study. Building and Environment, 32(3), 245-255.

[9] McManus, M. C., \& Taylor, C. M. (2015). The changing nature of life cycle assessment. Biomass and Bioenergy, 82, 13-26.

[10] Teşkilatı, D. P., Sanayii, K., İlaçları, T., \& Komisyonu, Ö. İ. (2001). Sekizinci Beş Yıllık Kalkınma Planı Kimya Sanayii (Tarım İlaçları) Özel İhtisas Komisyonu raporu. DPT.

[11] Tabone, M. D., Cregg, J. J., Beckman, E. J., \& Landis, A. E (2010). Sustainability metrics: life cycle assessment and green design in polymers. Environmental Science \& Technology, 44(21), 8264-8269. 